\section{What Can't You Do with Triptycenes? Boratriptycenes Take Lewis Acids to the Extreme}

Synthesis of

Materials and

Unnatural Products

\section{Key words}

Lewis acids

triptycenes

protodeboronation<smiles>Brc1ccccc1P(c1ccccc1Br)c1ccccc1Br</smiles>

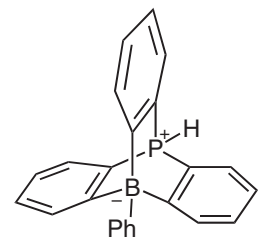

$50 \%$ yield

Lewis acidic nature of boratriptycenes:
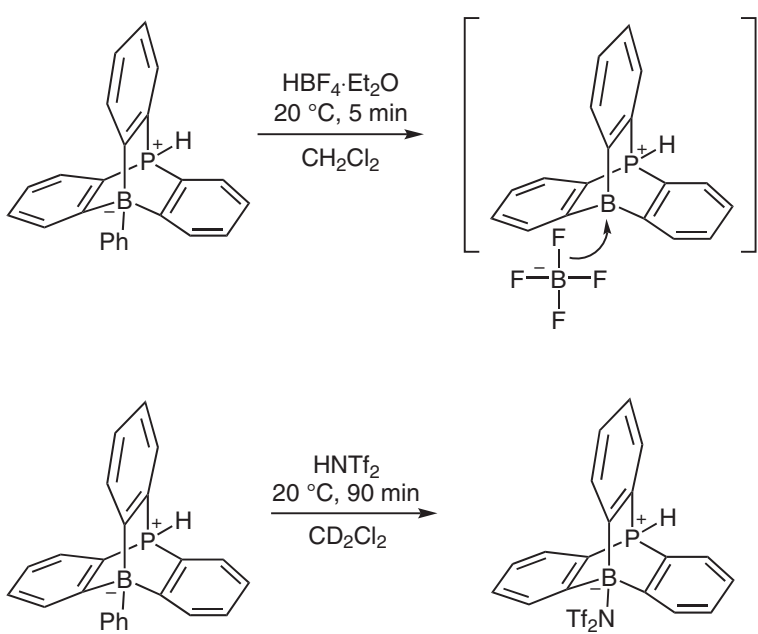
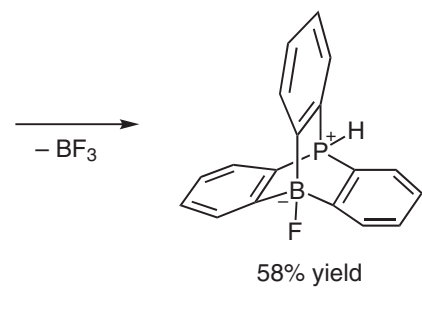

$58 \%$ yield
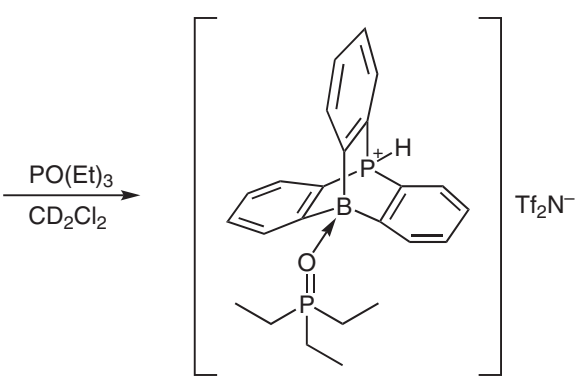

Significance: Trivalent organoboron compounds are an interesting class of materials with applications in Lewis acid catalyzed reactions. Here, Berionni and co-workers find that embedding boron in the carbon scaffold of triptycene greatly contributed to the increased Lewis acidity of the molecule. The boratriptycenes were found to bind various weak Lewis bases covalently.
Comment: While the synthesis of the 9-boratriptycene was unsuccessful, replacing the $\mathrm{C}-\mathrm{H}$ bridgehead with a phosphonium linker proved to be effective. The phosphonium moiety was also useful as a strong Brønsted acid. This is the first report to describe the coordination of the non-nucleophilic triflimide anion to a trivalent boron, emphasizing the unrivaled Lewis acidity of this molecule. 